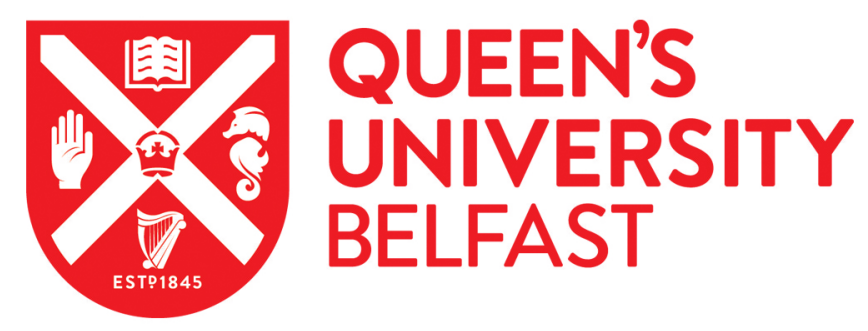

\title{
Prioritization of Outcomes in Efficacy and Effectiveness of Alcohol Brief Intervention Trials: International Multi-Stakeholder e-Delphi Consensus Study to Inform a Core Outcome Set
}

Shorter, G. W., Heather, N., Bray, J. W., Berman, A. H., Giles, E. L., O'Donnell, A. J., Barbosa, C., Clarke, M., Holloway, A., \& Newbury-Birch, D. (2019). Prioritization of Outcomes in Efficacy and Effectiveness of Alcohol Brief Intervention Trials: International Multi-Stakeholder e-Delphi Consensus Study to Inform a Core Outcome Set. Journal of Studies on Alcohol and Drugs, 80(3), 299-309. https://doi.org/10.15288/jsad.2019.80.299

Published in:

Journal of Studies on Alcohol and Drugs

Document Version:

Publisher's PDF, also known as Version of record

Queen's University Belfast - Research Portal:

Link to publication record in Queen's University Belfast Research Portal

\section{Publisher rights}

Copyright 2019 the authors.

This is an open access article published under a Creative Commons Attribution License (https://creativecommons.org/licenses/by/4.0/), which permits unrestricted use, distribution and reproduction in any medium, provided the author and source are cited.

\section{General rights}

Copyright for the publications made accessible via the Queen's University Belfast Research Portal is retained by the author(s) and / or other copyright owners and it is a condition of accessing these publications that users recognise and abide by the legal requirements associated with these rights.

Take down policy

The Research Portal is Queen's institutional repository that provides access to Queen's research output. Every effort has been made to ensure that content in the Research Portal does not infringe any person's rights, or applicable UK laws. If you discover content in the

Research Portal that you believe breaches copyright or violates any law, please contact openaccess@qub.ac.uk. 


\title{
Prioritization of Outcomes in Efficacy and Effectiveness of Alcohol Brief Intervention Trials: International Multi- Stakeholder e-Delphi Consensus Study to Inform a Core Outcome Set
}

\author{
GILLIAN W. SHORTER, B.SC., PH.D., ${ }^{a, b}, *$ NICK HEATHER, B.A., M.SC., PH.D., ${ }^{c}$ JEREMY W. BRAY, B.A., M.A., PH.D., ${ }^{d}$ \\ ANNE H. BERMAN, B.SC., M.SC., PH.D., ${ }^{e}$ EMMA L. GILES, B.SC., PH.D., ${ }^{b}$ AMY J. O’DONNELL, B.SC., PH.D., $f$ \\ CAROLINA BARBOSA, PHARM.D., M.SC., PH.D., ${ }^{g}$ MIKE CLARKE, B.A., D.PHIL., ${ }^{h}$ AISHA HOLLOWAY, B.SC., PH.D., ${ }^{i} \&$ \\ DOROTHY NEWBURY-BIRCH, B.A., PH.D. ${ }^{j}$ \\ aInstitute for Mental Health Sciences, School of Psychology, Ulster University, Coleraine, Northern Ireland \\ ${ }^{b}$ School of Health and Social Care, Teesside University, Middlesbrough, England \\ ${ }^{c}$ Faculty of Health \& Life Sciences, Northumbria University, Newcastle upon Tyne, England \\ ${ }^{d}$ Bryan School of Business \& Economics, University of North Carolina at Greensboro, Greensboro, North Carolina \\ ${ }^{e}$ Center for Psychiatry Research, Department of Clinical Neuroscience, Karolinska Institutet, \& Stockholm Health Care Services, \\ Stockholm County Council, Sweden \\ finstitute of Health and Society, Newcastle University, Newcastle upon Tyne, England \\ gBehavioral Health Economics Program, RTI International, Chicago, Illinois \\ ${ }^{h}$ Northern Ireland Methodology Hub, Queen's University of Belfast, Belfast, Northern Ireland \\ ${ }^{i}$ Nursing Studies, School of Health in Social Sciences, The University of Edinburgh, Edinburgh, Scotland \\ iSchool of Social Sciences, Humanities and Law, Teesside University, Middlesbrough, England
}

\begin{abstract}
Objective: Outcomes used in alcohol brief intervention trials vary considerably. Achieving consensus about key outcomes can enhance evidence synthesis and improve healthcare guidelines. This international, e-Delphi study sought to prioritize outcomes for alcohol brief intervention trials as part of a larger program of work develop an alcohol brief intervention core outcome set. Method: In total, 150 registrants from 19 countries, representing researchers, policymakers, and patients, participated in a two-round e-Delphi study. In Round 1, participants $(n=137)$ rated 86 outcomes, derived from a review of the literature and a patient and public involvement panel, by importance. In Round 2, participants $(n=114)$ received feedback on importance ratings for each outcome, and a reminder of their personal rating, before rating the outcomes for importance a second time. Seven additional outcomes suggested in Round 1 were added to the Round 2 questionnaire. We de-
\end{abstract}

fined consensus a priori as 70\% agreement across all stakeholder groups Results: Seven consumption outcomes met inclusion criteria: typical frequency, typical quantity, frequency of heavy drinking, alcohol-related problems, weekly drinks, at-risk drinking, and combined consumption measures. Others meeting the threshold were alcohol-related injury, quality of life, readiness to change, and intervention fidelity. Conclusions: This is the first international e-Delphi study to identify and prioritize outcomes for use in alcohol brief intervention trials. The use and reporting of outcomes in future alcohol brief intervention trials should improve evidence synthesis in systematic reviews and meta-analyses. Further work is required to refine these outcomes into a core outcome set that includes guidance for measurement of outcomes. (J. Stud. Alcohol Drugs, 80, 299-309, 2019)
$\mathrm{A}$ LCOHOL BRIEF INTERVENTIONS (ABIs) have emerged as the main approach to addressing hazardous and harmful alcohol use in a range of settings, including primary care, emergency departments, hospitals, online, criminal justice, workplaces, probation, and universities. According to U.K. National Institute for Health and Care Excellence (2010) guidance Public Health Guideline 24 (PH24), ABIs are suitable for non-treatment-seeking drinkers age 16 or older who are currently experiencing, or are at risk of experiencing, problems from their alcohol use.

Received: June 20, 2018. Revision: November 20, 2018.

This study was supported by Alcohol Research UK Research Innovation Grant No. R2016/04.

*Correspondence may be sent to Gillian W. Shorter, B.Sc., Ph.D., at the Institute for Mental Health Sciences, School of Psychology, Ulster University, Cromore Road, Coleraine, Northern Ireland, BT52 1SA, or via email at gw.shorter@ulster.ac.uk.
Designed to help drinkers reduce their alcohol consumption, ABIs typically consist of a short, single session of feedback and tailored advice (brief advice), or longer, motivationally based interventions that explore motivations for drinking and personal barriers to change (extended brief intervention) (Cunningham et al., 2017). Essential components of ABIs are defined here as the assessment of personal alcohol use and tailored feedback provided directly to the drinker.

Systematic reviews of ABI trials do not always agree on the efficacy and effectiveness of ABIs to change alcohol use (e.g., Davoren et al., 2016; Kaner et al., 2018; Khadjesari et al., 2011; White et al., 2010). There are many possible reasons for this disagreement, such as changes in the population being studied over time, changes in baseline drinking, variability in $\mathrm{ABI}$ content and reporting, and inclusion and exclusion criteria variations, among other issues. An avoidable source of disagreement in the literature, however, arises 
from the wide variation in outcomes used and the difficulty in combining diverse outcomes in meta-analyses (Cumming, 2013; Kaner et al., 2018). This can be variation in what outcome is measured or, for a given outcome, variation in how the outcome is measured.

Given the increasing role of systematic reviews and metaanalyses in determining health policy and the potential for outcome heterogeneity to compromise these reviews and analyses, there is a growing effort across a wide range of disciplines and disease categories to standardize trial outcomes (Williamson \& Clarke, 2012). The importance of standardizing trial outcome measurement is recognized by the Standard Protocol Items Recommendations for Interventional Trials (SPIRIT; Chan et al., 2013) and Consolidated Standards of Reporting Trials (CONSORT; Moher et al., 2001) statements, both of which recommend the use of a well-designed core outcome set. A formal process for defining a core outcome set has been established by the Core Outcome Measures in Effectiveness Trials (COMET) initiative (Williamson et al., 2012, 2017), and numerous studies using this process have been undertaken (Gargon et al., 2017). Given the current lack of a core outcome set for ABI trials and their increasing importance in alcohol policies worldwide, an ABI core outcome set is urgently needed.

The selection and application of a core outcome set are relevant to all ABI stakeholders, including beneficiaries (service users), practitioners, and policymakers (Williamson et al., 2012). A core outcome set ensures that outcomes meaningful to service users are routinely considered in clinical trials and that policymakers' perspectives are reflected in trial outcomes. Without a core outcome set, the selection of trial outcomes remains at the sole discretion of the involved researchers, whose decisions may be affected by implicit biases and cause unnecessary heterogeneity in the outcomes used across trials. The systematic review that informed this work assessed what outcomes are used and how they were measured in all ABI trials since 2000 across all settings. In brief, in 405 eligible trials (of 33,134 studies screened), 2,641 outcomes were reported, measured in approximately 1,560 different ways (Shorter et al., 2019). Because every researcher has the opportunity to select from a range of outcomes, better standardization of the minimum requirement to measure change will maximize the potential of $\mathrm{ABI}$ research to influence decision making, as it has in other research areas, such as eczema or rheumatoid arthritis (Boers, 1994; Schmitt et al., 2011).

To achieve improved standardization of the outcomes used in ABI trials, the Outcome Reporting in Brief Intervention Trials: Alcohol (ORBITAL) project (Shorter et al., 2017) is working to establish a core outcome set for ABIs using COMET procedures. Endorsed by the International Network on Brief Interventions for Alcohol and Other Drugs (INEBRIA) and with oversight by the INEBRIA Research Measurement Standardization Special Interest Group (RMS-
SIG), ORBITAL comprises three, inter-related studies to establish an ABI core outcome set (Shorter et al., 2017).

The first phase of the project was a comprehensive systematic review to determine what outcomes are reported in ABI trials (Shorter et al., 2019). The second phase, and the focus of this article, was an international, multi-perspective e-Delphi consensus study to prioritize outcomes for use as a minimum set of reported outcomes in all ABI efficacy and effectiveness trials. In phase three, the study will produce recommendations for a final set of $\mathrm{ABI}$ specific measures, using criteria recommended by the COnsensus-based Standards for the selection of health Measurement INstruments (COSMIN) initiative (Mokkink et al., 2016). Although ORBITAL is developing the core outcome set as a minimum data standard for ABI trials, the trials can use other measures alongside the core outcome set as appropriate.

Based on the COMET methodology (Williamson et al., 2017), ORBITAL places importance on involving a wide range of stakeholders in the development of the core outcome set; in particular, the client group considered to benefit most from an efficacious or effective intervention. As reported in this article, we used an e-Delphi approach to understand what outcomes are priorities for $\mathrm{ABI}$ stakeholders in addition to prioritizing outcome domains for use in $\mathrm{ABI}$ trials.

\section{Method}

We conducted an international, multi-stakeholder e-Delphi consensus study in two successive rounds. The e-Delphi approach is an iterative consensus technique that presents a series of sequential questionnaires asking individuals to rank outcomes in terms of priority for inclusion in a core outcome set for ABI efficacy or effectiveness trials. Ethical approval was granted by the School of Health and Social Care Ethics Committee at Teesside University (reference: 018/17).

The e-Delphi is an online implementation of the Delphi approach for consensus building (Hasson \& Keeney, 2011). The e-Delphi approach solicits the opinions of thought leaders and experts on a particular topic in successive rounds, with each round providing input to the next (Sinha et al., 2011). All Delphi studies use at least two rounds, but some use three or more. e-Delphi panelists are informed of the results of prior rounds and allowed to revise their opinion based on those results. The goal is to achieve a pre-defined threshold of consensus. Key to the e-Delphi approach is the anonymity of panelists. By ensuring that panel members remain anonymous throughout the process, panelists are free to revise their opinion without fear of reputational harm or to refuse to revise their opinion without pressure from the group to do so (Hasson et al., 2000).

\section{Participants}

There are no accepted guidelines for panel size to achieve stable consensus in an e-Delphi study. As such, 
we were guided by practicality, scope, and time available (Blackwood et al., 2015). Consistent with the purposive or criterion sampling approach used by many Delphi studies (Hasson et al., 2000), our sampling strategy focused on identifying electronic forums used by the relevant stakeholders and then allowing the sample to evolve organically as stakeholders shared the invitation to participate. Our sampling approach is best described as a purposive, snowball sampling approach. Participants were recruited in the following ways: emails to relevant mailing lists of researchers, practitioners, and policymakers in the field, such as the INEBRIA Google group; emails to corresponding authors of ABI trials identified by the systematic review; a tweet circulated by @teamalphatees at Teesside University; and emails forwarded by recruited participants to additional contacts with relevant expertise.

Participants were recruited between July 4 and August 1, 2017. Those recruited included the following: trial investigators and trialists, INEBRIA RMS-SIG members, executive leadership of scientific organizations, Cochrane Review Group on Drugs and Alcohol members, National Institute for Health and Care Excellence alcohol use disorder prevention PH24 membership group, statisticians, core outcome set developers, service users/patient and public representatives, practitioners, groups involved in developing ABI clinical guidance, funders, and research ethics committee members (Shorter et al., 2017).

Participants often held multiple roles. Consistent with COMET methodology, we included researchers, policymakers, and service users/patients in our sample of experts to ensure a broad representation of opinions. The patient perspective is particularly important to the COMET methodology because user input into this kind of study adds the lived experience of the alcohol consumer. Outcomes perceived to be relevant by stakeholders further removed from the user experience can appear less relevant to users (Henihan et al., 2015, 2016). Also, users can suggest outcomes not immediately apparent as important to researchers. Recruitment text and round instructions are available from the corresponding author. To minimize attrition between rounds, recruitment text stressed the importance of completing both rounds.

Given the organic nature of our recruitment procedure, it is not possible to establish exact numbers of individuals who received an invitation to participate during the recruitment window. For example, the INEBRIA Google group has 653 members. However, we were unable to identify which members actively participated in our Delphi survey from the group or determine whether any members subsequently forwarded the invitation to colleagues. Similarly, it is not possible to ascertain how many of the 458 @teamalphatees Twitter followers saw the e-Delphi invitation. Furthermore, the anonymous nature of the e-Delphi meant we were unable to track systematically the acceptance rate of the approximately 250 invitation emails we issued.
Thus, we cannot provide a response rate in a traditional sense. The relevance of a traditional response rate is unclear, given the purposive, anonymous, snowball sampling approach we used. Therefore, rather than focus on a response rate per se, we monitored the number of panelists in each of the three basic stakeholder types: researcher, policymaker, and patient. We did not attempt to "balance" the participants across types but rather tried to ensure a sufficient number of each type.

\section{The Delphi questionnaire and rounds}

The e-Delphi used a bespoke online e-management system, DelphiManager (Liverpool, UK), maintained by the COMET initiative to facilitate core outcome set development. In both rounds, participants scored each outcome using the Grading of Recommendations Assessment, Development, and Evaluations (GRADE) scale of 1-9, with 1-3 labeled not important for inclusion, 4-6 labeled important but not critical, and 7-9 labeled critical for inclusion (Guyatt et al., 2011). Outcomes were derived from the first 100 articles in a systematic review of existing ABI effectiveness and efficacy trials (Shorter et al., 2019; Registered at PROSPERO, CRD42016047185; Shorter et al., 2016). These articles were not randomly selected but did represent a range of ABI settings and the full spectrum of years from 2000 to 2016.

Current or former hazardous drinkers $(n=9)$ formed a patient and public involvement panel, some from an established service user representative group (Belfast Experts by Experience) and others known to the lead author as drinking hazardously or above (but not researchers, clinicians, or members of other professional groups related to drinking or other addictive behaviors). The current hazardous drinking individuals on this panel $(n=5)$ were recruited through personal invitation from the lead author and were verified as hazardous drinkers by an Alcohol Use Disorders Identification Test score of eight or more. The patient and public involvement panel added additional outcomes to the questionnaire at Round 1. Every outcome was given a descriptor. The outcomes were discussed and refined for clarity by the patient and public involvement panel and the authors.

In Round 1, there were 86 outcomes presented to participants. Participants could add additional outcomes and comment on the reason for their outcome ranking. Suggested outcomes from Round 1 were reviewed and coded to determine their novelty (i.e., that they were not covered by existing outcomes in the questionnaire). The additional outcomes and decisions made can be seen in the supplemental material that appears as an online-only addendum to the article on the journal's website. Round 2 included the 86 original outcomes, the seven additional outcomes suggested by respondents in Round 1, the individual's personal ranking, and rankings grouped by stakeholder group (research- 
ers, healthcare and other professionals, and service users/ representatives).

Round 1 and Round 2 both used the same GRADE ranking system. All those who registered in Round 1 were invited to take part, with Round 2 closing on September 12, 2017. Consensus was defined a priori (Shorter et al., 2017) as $70 \%$ or more of the respondents scoring an outcome from seven to nine and fewer than $15 \%$ scoring it one to three (Blackwood et al., 2015; Eleftheriadou et al., 2015). This would illustrate an outcome agreed as critically important by the majority and as of little or no importance by a small minority (Shorter et al., 2017). Although there is no formal guidance for the reporting of e-Delphi studies, we followed recommendations by Sinha et al. (2011). Participants received no financial incentive to participate.

\section{Results}

There were 150 total registrants. Overall, 137 took part in at least one question in Round 1 (including five partial completions), and 114 took part in at least one question in Round 2 (including 10 partial completions): these respondents are referred to as participants hereafter. In total, 107 took part in at least one question in both rounds, 30 completed Round 1 only, seven completed Round 2 only, and seven registered but did not complete either round. A single person's response contributed between $1.1 \%-0.7 \%$ (Round 1 ) and $1.4 \%-0.9 \%$ (Round 2) to a percentage total (variability range includes missing data or "prefer not to answer"). As noted in a recent systematic review (Boulkedid et al., 2011), few Delphi studies report response rates for all rounds; therefore, it is difficult to determine if our rate of attrition from Round 1 to Round 2 is typical. This same review found that the median number of invited participants in Delphi studies was only 17. Thus, we conclude that our sample size is more than sufficient. Further, because our sample was intentionally purposive, not representative, we also conclude that any attrition from Round 1 to Round 2 is not problematic.

Details of participants and registrants are given in Table 1. The largest proportions of participants were researchers, female, and from the United Kingdom or the United States. Because ABI "patients" are most often hazardous drinkers who are not treatment seeking and often do not consider themselves to be alcohol patients, this user group was the most problematic to identify and recruit. Consequently, they had the lowest representation across participant types.

In total, participants were from 19 countries (several noted "other" but without stating country name). The majority had been involved in at least one ABI trial (70.7\%), and approximately one quarter had been involved in four or more. Most participants had no experience of reviews of ABIs or of developing measurement instruments $(59.3 \%$ and $60.7 \%$, respectively).

In addition, the majority had no experience with core outcome set development (71.3\%). Of those with previous experience, most had been involved in developing one core outcome set. The majority of ABI trial experience was in a healthcare setting: $38.0 \%$ had experience in alcohol or drug treatment settings, $36.7 \%$ in primary care, $33.3 \%$ in outpatient care, $33.3 \%$ in inpatient care, and $31.3 \%$ in emergency care settings (participants could have experience in more than one group).

The ranking of consumption measures is given in Table 2. Based on Round 1 ranking, four met the $70 \%$ threshold. Upon review by participants in Round 2, seven met these criteria. These criteria were as follows: typical frequency, frequency of heavy drinking, number of drinks in a week, hazardous or harmful drinking, alcohol-related problems, combined consumption measure, and typical quantity. There was least change in views on alcohol-related problems, with an increase of $0.8 \%$ in those ranking this outcome critical for inclusion between rounds. By contrast, the largest increase in those ranking critical for inclusion was in the typical quantity outcome, which increased by $15 \%$.

Rankings of the remaining domains are given in Table 3. Biomarkers were typically under-ranked, with a higher proportion selecting unable to score than any other domain. Of those that were ranked, the highest ranked were levels of phosphatidylethanol and alanine aminotransferase. However, none met either threshold for scores in the critical for inclusion range or not important for inclusion range. In the resource use and economic factors domain, none met the $70 \%$ threshold for those in the critical for inclusion range. However, four met the lowered $60 \%$ threshold. These were alcohol-related injury, use, alcohol or drug treatment, emergency healthcare, and hospitalization.

In the life impact domain, the highest ranked outcome was quality of life. This outcome was ranked $79.4 \%$ in the critical for inclusion range at the end of Round 2, reflecting an increase of $16 \%$ from the corresponding range in Round 1. Only one of the health domain outcomes met the lowered criterion of $60 \%$ in the critical for inclusion range: psychological or mental health $(64.7 \%$ in the critical for inclusion range at Round 2). Only one item from the psychological factors domain met the $70 \%$ threshold of critical for inclusion range. This was interest in making changes around alcohol use. Finally, only one item in the intervention factors domain was ranked as critical for inclusion. This related to whether the intervention was delivered as planned. The ranking for this item was $81.4 \%$ in the critical for inclusion range in Round 2.

\section{Discussion}

Given that ABIs are a key component of alcohol policies worldwide, it is vital that policymakers, service commissioners, and practitioners are able to access and synthesize robust, consistent evidence to inform their implementation 
TABLE 1. Characteristics of registrants and participants in the e-Delphi survey Rounds 1 and 2

\begin{tabular}{|c|c|c|c|}
\hline Variable & $\begin{array}{c}\text { Registrants } \\
(n=150)\end{array}$ & $\begin{array}{l}\text { Round } 1 \\
(n=137)\end{array}$ & $\begin{array}{l}\text { Round } 2 \\
(n=114)\end{array}$ \\
\hline \multicolumn{4}{|l|}{ Stakeholder group } \\
\hline Researchers & $91(60.7 \%)$ & $87(63.5 \%)$ & $72(63.2 \%)$ \\
\hline $\begin{array}{l}\text { Healthcare and other professionals } \\
\text { (including policymakers) }\end{array}$ & $50(33.3 \%)$ & $42(30.7 \%)$ & $34(29.8 \%)$ \\
\hline Patient/public involvement panel & $9(6.0 \%)$ & $8(5.8 \%)$ & $8(7.0 \%)$ \\
\hline \multicolumn{4}{|l|}{ Gender } \\
\hline Male & $63(42.0 \%)$ & $61(44.5 \%)$ & $49(43.0 \%)$ \\
\hline Female & $85(56.7 \%)$ & $75(54.7 \%)$ & $64(56.1 \%)$ \\
\hline Trans* & $1(0.7 \%)$ & $1(0.7 \%)$ & $1(0.9 \%)$ \\
\hline Rather not say & $1(0.7 \%)$ & $0(0.0 \%)$ & $0(0.0 \%)$ \\
\hline \multicolumn{4}{|l|}{ Country } \\
\hline Argentina & $1(0.7 \%)$ & $1(0.7 \%)$ & $1(0.9 \%)$ \\
\hline Australia & $3(2.0 \%)$ & $3(2.2 \%)$ & $3(2.6 \%)$ \\
\hline Brazil & $1(0.7 \%)$ & $1(0.7 \%)$ & $1(0.9 \%)$ \\
\hline Canada & $2(1.3 \%)$ & $2(1.5 \%)$ & $2(1.8 \%)$ \\
\hline Denmark & $1(0.7 \%)$ & $1(0.7 \%)$ & $1(0.9 \%)$ \\
\hline France & $1(0.7 \%)$ & $1(0.7 \%)$ & $1(0.9 \%)$ \\
\hline Germany & $3(2.0 \%)$ & $2(1.5 \%)$ & $2(1.8 \%)$ \\
\hline Ireland & $1(0.7 \%)$ & $1(0.7 \%)$ & $1(0.9 \%)$ \\
\hline Italy & $2(1.3 \%)$ & $2(1.5 \%)$ & $1(0.9 \%)$ \\
\hline Mexico & $1(0.7 \%)$ & $0(0.0 \%)$ & $0(0.0 \%)$ \\
\hline Netherlands & $4(2.7 \%)$ & $4(2.9 \%)$ & $2(1.8 \%)$ \\
\hline Other (not specified) & $3(2.0 \%)$ & $3(2.2 \%)$ & $3(2.7 \%)$ \\
\hline Portugal & $1(0.7 \%)$ & $1(0.7 \%)$ & $1(0.9 \%)$ \\
\hline Spain & $1(0.7 \%)$ & $1(0.7 \%)$ & $1(0.9 \%)$ \\
\hline Sweden & $3(2.0 \%)$ & $3(2.2 \%)$ & $2(1.8 \%)$ \\
\hline Switzerland & $7(4.7 \%)$ & $7(5.1 \%)$ & $6(5.3 \%)$ \\
\hline Thailand & $2(1.3 \%)$ & $2(1.5 \%)$ & $1(0.9 \%)$ \\
\hline Uganda & $1(0.7 \%)$ & $1(0.7 \%)$ & $1(0.9 \%)$ \\
\hline United Kingdom & $68(45.3 \%)$ & $59(43.1 \%)$ & $48(42.1 \%)$ \\
\hline United States & $44(29.3 \%)$ & $42(30.7 \%)$ & $36(31.6 \%)$ \\
\hline \multicolumn{4}{|c|}{$\begin{array}{l}\text { No. of alcohol brief intervention trials you } \\
\text { have been involved in }\end{array}$} \\
\hline 0 & $45(29.3 \%)$ & $37(27.0 \%)$ & $30(26.3 \%)$ \\
\hline 1 & $22(14.7 \%)$ & $18(13.1 \%)$ & $15(13.2 \%)$ \\
\hline 2 & $30(20.0 \%)$ & $30(21.9 \%)$ & $27(23.7 \%)$ \\
\hline 3 & $15(10.0 \%)$ & $14(10.2 \%)$ & $12(10.5 \%)$ \\
\hline$\geq 4$ & $39(26.0 \%)$ & $38(27.7 \%)$ & $30(26.3 \%)$ \\
\hline \multicolumn{4}{|c|}{$\begin{array}{l}\text { No. of systematic reviews that include } \\
\text { alcohol brief intervention trials you have } \\
\text { been involved in }\end{array}$} \\
\hline 0 & $89(59.3 \%)$ & $80(58.4 \%)$ & $67(58.8 \%)$ \\
\hline 1 & $26(17.23)$ & $23(16.8 \%)$ & $20(17.5 \%)$ \\
\hline 2 & $18(12.0 \%)$ & $17(12.4 \%)$ & $16(14.0 \%)$ \\
\hline
\end{tabular}

(Babor et al., 2007; Bernstein et al., 2010). A key factor currently impeding existing evidence synthesis efforts is a lack of standardized outcomes used in ABI trials (Shorter et al., 2017). As seen in other fields, standardization of outcomes will improve the ability of others to integrate and evaluate the literature. Thus, the COMET initiative has developed a formal, multi-phase methodology (Williamson et al., 2012, 2017) to support researchers in efforts to establish a core outcome set.

The multi-phase ORBITAL project seeks to establish a core outcome set for ABI trials using the COMET methodology. In doing so, ORBITAL aims to simplify and inform future ABI trial decision making (Daykin et al., 2016, 2017) and to move beyond individual trial researcher preference as the primary vehicle by which outcomes are chosen to one of consensus between stakeholders (Williamson et al., 2017). This study presents the results of the e-Delphi study conducted in phase two of the ORBITAL project and represents the first attempt to seek international, multi-stakeholder perspectives on which outcomes should be prioritized for ABI trials.

The results of our e-Delphi study suggest that considerable standardization of outcomes used in the ABI trials is possible. A systematic review conducted as part of the larger ORBITAL effort (Shorter et al., 2019) found that 2,641 outcomes, measured in approximately 1,560 different ways, were reported in ABI trials, suggesting substantial variability in the outcomes that the ABI research community prioritizes. Yet, our e-Delphi study found that only nine outcomes met our a priori consensus threshold ( $70 \%$ agreement), seven of 


\begin{tabular}{|c|c|c|c|}
\hline Variable & $\begin{array}{l}\text { Registrants } \\
(n=150)\end{array}$ & $\begin{array}{l}\text { Round } 1 \\
(n=137)\end{array}$ & $\begin{array}{l}\text { Round } 2 \\
(n=114)\end{array}$ \\
\hline 3 & $9(6.0 \%)$ & $9(6.6 \%)$ & $7(6.1 \%)$ \\
\hline$\geq 4$ & $8(5.3 \%)$ & $8(5.8 \%)$ & $4(3.5 \%)$ \\
\hline \multicolumn{4}{|l|}{$\begin{array}{l}\text { No. of measurement instruments developed } \\
\text { that could be used as an outcome in an } \\
\text { alcohol brief intervention trial }\end{array}$} \\
\hline 0 & $92(60.7 \%)$ & $82(59.9 \%)$ & $67(58.8 \%)$ \\
\hline 1 & $34(22.7 \%)$ & $30(21.9 \%)$ & $26(22.8 \%)$ \\
\hline 2 & $12(8.0 \%)$ & $12(8.8 \%)$ & $10(8.8 \%)$ \\
\hline 3 & $6(4.0 \%)$ & $6(4.4 \%)$ & $5(4.4 \%)$ \\
\hline$\geq 4$ & $7(4.7 \%)$ & $7(5.1 \%)$ & $6(5.3 \%)$ \\
\hline \multicolumn{4}{|l|}{$\begin{array}{l}\text { No. of core outcome sets you have been } \\
\text { involved in developing (including as a } \\
\text { Delphi participant) }\end{array}$} \\
\hline 0 & $107(71.3 \%)$ & $97(70.8 \%)$ & $83(72.8 \%)$ \\
\hline 1 & $20(13.3 \%)$ & $20(14.6 \%)$ & $16(14.0 \%)$ \\
\hline 2 & $9(6.0 \%)$ & $8(5.8 \%)$ & $5(4.4 \%)$ \\
\hline 3 & $3(2.0 \%)$ & $3(2.2 \%)$ & $3(2.6 \%)$ \\
\hline$\geq 4$ & $11(7.3 \%)$ & $9(6.6 \%)$ & $7(6.1 \%)$ \\
\hline \multicolumn{4}{|l|}{$\begin{array}{l}\text { In which setting do you have alcohol brief } \\
\text { intervention experience? }\end{array}$} \\
\hline Alcohol or drug treatment & $57(38.0 \%)$ & $51(37.2 \%)$ & $42(36.8 \%)$ \\
\hline $\begin{array}{l}\text { Criminal justice (prison, probation, or } \\
\text { other setting) }\end{array}$ & $22(14.7 \%)$ & $21(15.3 \%)$ & $17(14.9 \%)$ \\
\hline $\begin{array}{l}\text { Emergency care (e.g., trauma center, } \\
\text { emergency room) }\end{array}$ & $47(31.3 \%)$ & $45(32.8 \%)$ & $35(30.7 \%)$ \\
\hline $\begin{array}{l}\text { Inpatient hospital care (not alcohol/drug } \\
\text { treatment/emergency care) }\end{array}$ & $50(33.3 \%)$ & $47(34.3 \%)$ & $37(32.5 \%)$ \\
\hline $\begin{array}{l}\text { Outpatient hospital care (e.g., sexual } \\
\text { health clinic) }\end{array}$ & $50(33.3 \%)$ & $46(33.6 \%)$ & $37(32.5 \%)$ \\
\hline Mobile-based brief interventions & $28(18.7 \%)$ & $27(19.7 \%)$ & $23(20.2 \%)$ \\
\hline Online web-based brief interventions & $42(28.0 \%)$ & $40(29.2 \%)$ & $35(30.7 \%)$ \\
\hline Pharmacy or drug store brief interventions & $8(5.3 \%)$ & $8(5.8 \%)$ & $4(3.5 \%)$ \\
\hline $\begin{array}{l}\text { Primary care (general practice or family } \\
\text { physician) }\end{array}$ & $55(36.7 \%)$ & $52(38.0 \%)$ & $42(36.8 \%)$ \\
\hline Schools & $21(14.0 \%)$ & $20(14.6 \%)$ & $16(14.0 \%)$ \\
\hline Universities and colleges & $43(28.7 \%)$ & $41(29.9 \%)$ & $33(28.9 \%)$ \\
\hline Veterans/military & $2(1.3 \%)$ & $2(1.5 \%)$ & $2(1.8 \%)$ \\
\hline $\begin{array}{l}\text { Workplaces (includes employee assistance } \\
\text { programs/job centers) }\end{array}$ & $24(16.0 \%)$ & $22(16.1 \%)$ & $14(12.3 \%)$ \\
\hline Licensed premises & $5(3.3 \%)$ & $5(3.6 \%)$ & $1(0.9 \%)$ \\
\hline $\begin{array}{l}\text { General population, community, or } \\
\text { convenience samples }\end{array}$ & $8(5.3 \%)$ & $8(5.8 \%)$ & $7(6.1 \%)$ \\
\hline Social services & $2(1.3 \%)$ & $2(1.5 \%)$ & $1(0.9 \%)$ \\
\hline
\end{tabular}

Note: No. $=$ number.

which were related to alcohol consumption. Relaxing our a priori threshold (from $70 \%$ to $60 \%$ agreement) resulted in the identification of an additional five consensus outcomes, four of which were related to healthcare use.

Thus, the findings from our e-Delphi study suggest that much of the variation in the outcomes used in the ABI literature could be driven by idiosyncratic decisions by individual researchers regarding the specific outcomes for any given trial, as opposed to by a fundamental diversity of relevant outcome domains. If this conclusion is correct, the ORBITAL effort to develop an ABI core outcome set will greatly improve the ability of $\mathrm{ABI}$ researchers to provide consistent, policy-relevant evidence across studies on the outcomes they view as most important.

The validity of this conclusion, however, depends on the composition of our e-Delphi panel. Recommended best practice (Blackwood et al., 2015) is to include a diverse set of panelists in our e-Delphi study. Diverse perspectives are likely to result in wider acceptance of the prioritized outcomes deemed critical to include in ABI studies, although we note priorities may differ in different participant groups and ABI settings (Hula et al., 2014). In this respect, it is notable that our participants represented a range of countries (19 countries across 6 continents) and stakeholder groups (researchers, policymakers, and service users/patients) and, thus, captured a broad range of perspectives.

At the same time, it is important to acknowledge that most participants were from the United Kingdom or the United States, and participants from South America and Asia were underrepresented in our survey respondents. 
TABLE 2. Consumption domain rankings from e-Delphi questionnaires in Rounds 1 and 2

\begin{tabular}{|c|c|c|c|c|c|c|c|c|}
\hline \multirow[b]{2}{*}{ Consumption } & \multicolumn{4}{|c|}{ Round 1} & \multicolumn{4}{|c|}{ Round 2} \\
\hline & $n$ & $\begin{array}{l}\text { Scored } \\
1-3 \\
n(\%)\end{array}$ & $\begin{array}{l}\text { Scored } \\
4-6 \\
n(\%)\end{array}$ & $\begin{array}{l}\text { Scored } \\
7-9 \\
n(\%)\end{array}$ & $n$ & $\begin{array}{l}\text { Scored } \\
1-3 \\
n(\%)\end{array}$ & $\begin{array}{l}\text { Scored } \\
4-6 \\
n(\%)\end{array}$ & $\begin{array}{l}\text { Scored } \\
7-9 \\
n(\%)\end{array}$ \\
\hline $\begin{array}{l}\text { How often (frequency) a person drinks heavily } \\
\text { or large number of drinks on occasion }\end{array}$ & 136 & $3(2.2 \%)$ & $20(14.7 \%)$ & $113(83.1 \%)$ & 105 & $1(1.0 \%)$ & $6(5.7 \%)$ & $98(93.3 \%)$ \\
\hline $\begin{array}{l}\text { Total number of standard drinks consumed } \\
\text { in a week }\end{array}$ & 136 & $2(1.5 \%)$ & $28(20.6 \%)$ & $106(77.9 \%)$ & 107 & $2(1.9 \%)$ & $8(7.5 \%)$ & $97(90.7 \%)$ \\
\hline How often (frequency) a person drinks alcohol & 136 & $3(2.2 \%)$ & $32(23.5 \%)$ & $101(74.3 \%)$ & 105 & $2(1.9 \%)$ & $12(11.4 \%)$ & $91(86.7 \%)$ \\
\hline $\begin{array}{l}\text { Drinking at a level that puts you at risk of harm } \\
\text { (hazardous or harmful drinking) }\end{array}$ & 136 & $4(2.9 \%)$ & $39(28.7 \%)$ & $93(68.4 \%)$ & 104 & $1(1.0 \%)$ & $18(17.3 \%)$ & $85(81.7 \%)$ \\
\hline $\begin{array}{l}\text { Alcohol-related problems or consequences } \\
\text { due to alcohol use }\end{array}$ & 134 & $2(1.5 \%)$ & $28(20.9 \%)$ & $108(80.6 \%)$ & 113 & $0(0.0 \%)$ & $21(18.6 \%)$ & $92(81.4 \%)$ \\
\hline $\begin{array}{l}\text { Combined consumption measure that takes into } \\
\text { consideration one or more consumption } \\
\text { measures together (e.g., frequency, quantity, } \\
\text { or frequency of heavy drinking together in } \\
\text { one measure) }\end{array}$ & 136 & $6(4.4 \%)$ & $38(27.9 \%)$ & $92(67.6 \%)$ & 104 & $4(3.8 \%)$ & $16(15.4 \%)$ & $84(80.8 \%)$ \\
\hline $\begin{array}{l}\text { Typical number of drinks consumed in a } \\
\text { drinking occasion }\end{array}$ & 136 & $5(3.7 \%)$ & $55(40.4 \%)$ & $76(55.9 \%)$ & 102 & $2(1.9 \%)$ & $28(27.2 \%)$ & $73(70.9 \%)$ \\
\hline $\begin{array}{l}\text { Abuse symptomatology (severity of the } \\
\text { symptoms of alcohol abuse; excessive use) } \\
\text { Days abstinent-number of days in which }\end{array}$ & 135 & $10(7.4 \%)$ & $80(59.3 \%)$ & $65(48.1 \%)$ & 109 & $5(4.6 \%)$ & $49(45.0 \%)$ & $55(50.5 \%)$ \\
\hline a person does not drink/abstains from alcohol & 133 & $15(11.3 \%)$ & $64(48.1 \%)$ & $54(40.6 \%)$ & 108 & $12(11.1 \%)$ & $51(47.2 \%)$ & $45(41.7 \%)$ \\
\hline $\begin{array}{l}\text { Dependence symptomatology (severity of the } \\
\text { symptoms of alcohol dependence; physical } \\
\text { or psychological need to drink alcohol) }\end{array}$ & 134 & $16(11.9 \%)$ & $102(76.1 \%)$ & $48(35.8 \%)$ & 109 & $6(5.5 \%)$ & $65(59.6 \%)$ & $38(34.9 \%)$ \\
\hline $\begin{array}{l}\text { Drinking above the government guidelines } \\
\text { for low-risk drinking in a given country }\end{array}$ & 136 & $24(17.6 \%)$ & $61(44.9 \%)$ & $51(37.5 \%)$ & 102 & $18(17.6 \%)$ & $51(50.0 \%)$ & $33(32.4 \%)$ \\
\hline $\begin{array}{l}\text { Number of drinks consumed in a month or } \\
\text { other period }\end{array}$ & 136 & $31(22.8 \%)$ & $63(46.3 \%)$ & $42(30.9 \%)$ & $\begin{array}{l}104 \\
104\end{array}$ & $23(22.1 \%)$ & $\begin{array}{l}51(49.0 \%) \\
68(65.4 \%)\end{array}$ & $30(28.8 \%)$ \\
\hline $\begin{array}{l}\text { The use of alcohol with another drug } \\
\text { (e.g., tobacco or an illegal drug) at the same } \\
\text { time or in the same period }\end{array}$ & 135 & $24(17.8 \%)$ & $76(56.3 \%)$ & $35(25.9 \%)$ & 104 & $15(14.4 \%)$ & $62(61.4 \%)$ & $26(23.8 \%)$ \\
\hline $\begin{array}{l}\text { How often (frequency) a person drinks enough } \\
\text { to feel drunk/intoxicated }\end{array}$ & 136 & $22(16.2 \%)$ & $67(49.3 \%)$ & $47(34.6 \%)$ & 104 & $16(15.4 \%)$ & $67(64.4 \%)$ & $21(20.2 \%)$ \\
\hline $\begin{array}{l}\text { Drinks consumed in the heaviest week of } \\
\text { drinking in a given period }\end{array}$ & 136 & $18(13.2 \%)$ & $79(58.1 \%)$ & $39(28.7 \%)$ & 104 & $12(11.5 \%)$ & $76(73.1 \%)$ & $16(15.4 \%)$ \\
\hline $\begin{array}{l}\text { Blood alcohol concentration (levels } \\
\text { of alcohol in the blood; may be measured using } \\
\text { a breath alcohol analysis or calculated } \\
\text { based on reports of alcohol consumption) }\end{array}$ & 136 & $53(39.0 \%)$ & $60(44.1 \%)$ & $23(16.9 \%)$ & 108 & $42(38.9 \%)$ & $53(49.1 \%)$ & $13(12.0 \%)$ \\
\hline $\begin{array}{l}\text { Matching goals set before drinking about how } \\
\text { much alcohol you plan to drink or how long } \\
\text { you plan to drink for }\end{array}$ & 134 & $39(29.1 \%)$ & $71(53.0 \%)$ & $24(17.9 \%)$ & 104 & $23(22.1 \%)$ & $73(70.2 \%)$ & $8(7.7 \%)$ \\
\hline Time spent drinking alcohol & 136 & $51(37.5 \%)$ & $68(50.0 \%)$ & $17(12.5 \%)$ & 103 & $50(48.5 \%)$ & $49(47.6 \%)$ & $4(3.9 \%)$ \\
\hline Type of drink consumed & 136 & $68(50.0 \%)$ & $53(39.0 \%)$ & $15(11.0 \%)$ & 102 & $67(65.7 \%)$ & $31(30.4 \%)$ & $4(3.9 \%)$ \\
\hline $\begin{array}{l}\text { If your drinking matches the report of someone } \\
\text { who was there at the same time }\end{array}$ & 135 & $73(54.1 \%)$ & $59(43.7 \%)$ & $3(2.2 \%)$ & 104 & $74(71.2 \%)$ & $29(27.9 \%)$ & $1(1.0 \%)$ \\
\hline $\begin{array}{l}\text { How much alcohol a family member or partner } \\
\text { drinks; or other people who are similar to the } \\
\text { participant }\end{array}$ & 135 & $73(54.1 \%)$ & $53(39.3 \%)$ & $9(6.7 \%)$ & 104 & $67(64.4 \%)$ & $37(35.6 \%)$ & $0(0.0 \%)$ \\
\hline
\end{tabular}

Therefore, we must be cautious about the cultural relevance of prioritized outcomes in these locations (Hula et al., 2014). Further, most panelists were researchers, which may have overrepresented the consensus views of ABI researchers compared with other important perspectives, such as those of healthcare professionals, policymakers, and patient or public representatives.

It was notable that despite a wide range of critical outcomes identified by the panel, no critical outcomes were identified in the biomarkers domain. We can only specu- late as to why no biomarker measure reached the critical threshold. It may be that biomarker measures were less well understood by our online Delphi participants. However, it is also important to note that they are less commonly reported in ABI trials (Kypri, 2007). This may be because biomarkers are generally considered more relevant to assessing alcohol dependence; are known to have poor sensitivity and/or specificity in determining hazardous or harmful drinking; and/or are more inconvenient, time consuming, and expensive to use in comparison to self-report measures (Allen \& Litten, 
TABLE 3. Rankings from e-Delphi Rounds 1 and 2 in the biomarkers, economic factors/resource use, health, psychological factors, intervention factors, and life impact domains

\begin{tabular}{|c|c|c|c|c|c|c|c|c|}
\hline \multirow[b]{2}{*}{ Consumption } & \multicolumn{4}{|c|}{ Round 1} & \multicolumn{4}{|c|}{ Round 2} \\
\hline & $n$ & $\begin{array}{l}\text { Scored } \\
1-3 \\
n(\%)\end{array}$ & $\begin{array}{l}\text { Scored } \\
4-6 \\
n(\%)\end{array}$ & $\begin{array}{l}\text { Scored } \\
7-9 \\
n(\%)\end{array}$ & $n$ & $\begin{array}{l}\text { Scored } \\
1-3 \\
n(\%)\end{array}$ & $\begin{array}{l}\text { Scored } \\
4-6 \\
n(\%)\end{array}$ & $\begin{array}{l}\text { Scored } \\
7-9 \\
n(\%)\end{array}$ \\
\hline \multicolumn{9}{|l|}{ Biomarkers } \\
\hline $\begin{array}{l}\text { Phosphatidylethanol (PETH) suggested by three } \\
\text { individuals and scored } 8,7 \text {, and } 4\end{array}$ & \multicolumn{4}{|c|}{$\mathrm{N} / \mathrm{A}-$ not included in Round 1} & 76 & $20(26.3 \%)$ & $39(51.3 \%)$ & $17(22.4 \%)$ \\
\hline Alanine aminotransferase & 91 & $25(27.5 \%)$ & $51(56.0 \%)$ & $15(16.5 \%)$ & 81 & $20(24.7 \%)$ & $48(59.3 \%)$ & $13(16.0 \%)$ \\
\hline Gamma-glutamyltransferase & 93 & $28(30.1 \%)$ & $48(51.6 \%)$ & $17(18.3 \%)$ & 79 & $23(29.1 \%)$ & $44(55.7 \%)$ & $12(15.2 \%)$ \\
\hline Analyzing hair for ethyl-glucuronide suggested by & \multirow{2}{*}{\multicolumn{4}{|c|}{$\mathrm{N} / \mathrm{A}-$ not included in Round 1}} & & & & \\
\hline two participants scoring 4 and 7 & & & & & 79 & $32(40.5 \%)$ & $37(46.8 \%)$ & $10(12.7 \%)$ \\
\hline Aspartate aminotransferase & 89 & $26(29.2 \%)$ & $52(58.4 \%)$ & $11(12.4 \%)$ & 78 & $23(29.5 \%)$ & $46(59.0 \%)$ & $9(11.5 \%)$ \\
\hline Mean corpuscular volume (MCV) & 92 & $34(37.0 \%)$ & $46(50.0 \%)$ & $12(13.0 \%)$ & 78 & $30(38.5 \%)$ & $40(51.3 \%)$ & $8(10.3 \%)$ \\
\hline $\begin{array}{l}\text { Levels of whole blood-associated acetaldehyde } \\
\text { suggested by one participant and scored } 6\end{array}$ & \multicolumn{4}{|c|}{$\mathrm{N} / \mathrm{A} \longrightarrow$ not included in Round 1} & 74 & $24(32.4 \%)$ & & $7(9.5 \%)$ \\
\hline Carbohydrate-deficient transferrin & 92 & $25(27.2 \%)$ & $48(52.2 \%)$ & $19(20.7 \%)$ & 79 & $20(25.3 \%)$ & $\begin{array}{l}43(58.1 \%) \\
44(55.7 \%)\end{array}$ & $15(9.0 \%)$ \\
\hline \multicolumn{9}{|l|}{ Economic factors/resource use } \\
\hline $\begin{array}{l}\text { Alcohol-related injury (physical injury as a result } \\
\text { of alcohol use) }\end{array}$ & 130 & $3(2.3 \%)$ & $44(33.8 \%)$ & $83(63.8 \%)$ & 102 & $5(4.9 \%)$ & $26(25.5 \%)$ & $71(69.6 \%)$ \\
\hline $\begin{array}{l}\text { Use of drug/alcohol treatment in a healthcare setting } \\
\text { or by a healthcare professional }\end{array}$ & 130 & $11(8.5 \%)$ & $49(37.7 \%)$ & $70(53.8 \%)$ & 102 & $6(5.9 \%)$ & $32(31.4 \%)$ & $64(62.7 \%)$ \\
\hline Use of emergency healthcare services & 130 & $12(9.2 \%)$ & $48(36.9 \%)$ & $70(53.8 \%)$ & 102 & $6(5.9 \%)$ & $34(33.3 \%)$ & $62(60.8 \%)$ \\
\hline $\begin{array}{l}\text { Hospitalizations (inpatient healthcare services in a } \\
\text { ward other than the emergency room) }\end{array}$ & 129 & $8(6.2 \%)$ & $51(39.5 \%)$ & $70(54.3 \%)$ & 101 & $5(5.0 \%)$ & $35(34.7 \%)$ & $61(60.4 \%)$ \\
\hline $\begin{array}{l}\text { Alcohol-related driving offenses/impaired driving } \\
\text { (including drink driving or accidents) }\end{array}$ & 131 & $9(6.9 \%)$ & $48(36.6 \%)$ & $74(56.5 \%)$ & 102 & $6(5.9 \%)$ & $40(39.2 \%)$ & $56(54.9 \%)$ \\
\hline $\begin{array}{l}\text { Use of primary healthcare services (e.g., general } \\
\text { practice/primary care/family physician) }\end{array}$ & 130 & $15(11.5 \%)$ & $55(42.3 \%)$ & $60(46.2 \%)$ & 102 & $10(9.8 \%)$ & $37(36.3 \%)$ & $55(53.9 \%)$ \\
\hline $\begin{array}{l}\text { Seeking help for alcohol or drugs not from a } \\
\text { healthcare provider }\end{array}$ & 128 & $19(14.8 \%)$ & $61(47.7 \%)$ & $48(37.5 \%)$ & 100 & $10(10.0 \%)$ & $44(44.0 \%)$ & $46(46.0 \%)$ \\
\hline $\begin{array}{l}\text { General healthcare use (an overall measure of the use } \\
\text { of healthcare services) }\end{array}$ & 130 & $20(15.4 \%)$ & $63(48.5 \%)$ & $47(36.2 \%)$ & 101 & $9(8.9 \%)$ & $50(49.5 \%)$ & $42(41.6 \%)$ \\
\hline $\begin{array}{l}\text { Alcohol-related offenses (may relate to the setting, } \\
\text { e.g., alcohol-related violence or university rule } \\
\text { violations) }\end{array}$ & 131 & $10(7.6 \%)$ & $71(54.2 \%)$ & $50(38.2 \%)$ & 102 & $8(7.8 \%)$ & $56(54.9 \%)$ & $38(37.3 \%)$ \\
\hline $\begin{array}{l}\text { General accident costs (not just alcohol-related } \\
\text { accidents) }\end{array}$ & 129 & $31(24.0 \%)$ & $55(43.4 \%)$ & $42(32.6 \%)$ & 101 & $25(24.8 \%)$ & $53(52.5 \%)$ & $23(22.8 \%)$ \\
\hline $\begin{array}{l}\text { General criminal justice costs (not those directly } \\
\text { related to an alcohol offense) }\end{array}$ & 129 & $36(27.9 \%)$ & $56(43.4 \%)$ & $38(29.0 \%)$ & 101 & $30(29.7 \%)$ & $50(49.5 \%)$ & $21(20.8 \%)$ \\
\hline $\begin{array}{l}\text { Prescribed medication use (medication with a } \\
\text { prescription from a doctor) }\end{array}$ & 129 & $34(26.4 \%)$ & $63(48.8 \%)$ & $32(24.8 \%)$ & 100 & $22(22.0 \%)$ & $59(59.0 \%)$ & $19(19.0 \%)$ \\
\hline $\begin{array}{l}\text { Social service use (e.g., child protection; government- } \\
\text { sponsored unemployment support) }\end{array}$ & 126 & $21(16.7 \%)$ & $76(60.3 \%)$ & $29(23.0 \%)$ & 100 & $21(21.0 \%)$ & $60(60.0 \%)$ & $19(19.0 \%)$ \\
\hline Use of pharmacies or drug store advice & 129 & $46(35.7 \%)$ & $65(50.4 \%)$ & $18(14.0 \%)$ & 99 & $42(42.4 \%)$ & $50(50.5 \%)$ & $7(7.1 \%)$ \\
\hline Over-the-counter medication use & 126 & $49(38.9 \%)$ & $64(50.8 \%)$ & $13(10.3 \%)$ & 99 & $39(39.4 \%)$ & $55(55.6 \%)$ & $5(5.1 \%)$ \\
\hline \multicolumn{9}{|l|}{ Life impact } \\
\hline $\begin{array}{l}\text { Quality of life (the standard of health/comfort/ } \\
\text { happiness experienced by an individual) }\end{array}$ & 131 & $6(4.6 \%)$ & $42(32.1 \%)$ & $83(63.4 \%)$ & 102 & $2(2.0 \%)$ & $19(18.6 \%)$ & $81(79.4 \%)$ \\
\hline $\begin{array}{l}\text { Alcohol causing harm to other people-recommended } \\
\text { by one participant and scored } 7\end{array}$ & \multicolumn{4}{|c|}{$\mathrm{N} / \mathrm{A}-$ not included in Round 1} & 101 & $10(9.9 \%)$ & $55(54.5 \%)$ & $36(35.6 \%)$ \\
\hline $\begin{array}{l}\text { Workplace or college/university productivity (such as } \\
\text { the ability to work; or ability to meet deadlines } \\
\text { or targets) }\end{array}$ & 131 & $21(16.0 \%)$ & $72(55.0 \%)$ & $38(29.0 \%)$ & 102 & $14(13.7 \%)$ & $66(64.7 \%)$ & $22(21.6 \%)$ \\
\hline $\begin{array}{l}\text { Ability to participate in society; or quality of } \\
\text { relationships (e.g., within a family) }\end{array}$ & 131 & $16(12.2 \%)$ & $74(56.5 \%)$ & 41( & 102 & $8(7.8 \%)$ & $73(71.6 \%)$ & $21(20.6 \%)$ \\
\hline Satisfaction with social roles and activities & 131 & $18(13.7 \%)$ & $76(58.0 \%)$ & $37(28.2 \%)$ & 102 & $13(12.7 \%)$ & $75(73.5 \%)$ & $14(13.7 \%)$ \\
\hline $\begin{array}{l}\text { Improvement in finances (money available to spend } \\
\text { on other things) - suggested by one participant } \\
\text { and scored } 6\end{array}$ & & \multicolumn{3}{|c|}{$\mathrm{N} / \mathrm{A}-$ not included in Round 1} & 102 & $28(27.5 \%)$ & $68(66.7 \%)$ & $6(5.9 \%)$ \\
\hline \multicolumn{9}{|l|}{ Health } \\
\hline $\begin{array}{l}\text { Psychological/mental health (unpleasant feelings that } \\
\text { affect ability to live life) }\end{array}$ & 131 & $4(3.1 \%)$ & $52(39.7 \%)$ & $76(55.9 \%)$ & 102 & $5(4.9 \%)$ & $31(30.4 \%)$ & $66(64.7 \%)$ \\
\hline Overall health or how healthy the person feels & 131 & $7(5.3 \%)$ & $60(45.8 \%)$ & $64(48.9 \%)$ & 102 & $4(3.9 \%)$ & $44(43.1 \%)$ & $54(52.9 \%)$ \\
\hline $\begin{array}{l}\text { Risk of alcohol withdrawal symptoms (like delirium } \\
\text { tremens) }\end{array}$ & 126 & $21(16.7 \%)$ & $70(55.1 \%)$ & $35(27.8 \%)$ & 100 & $13(13.0 \%)$ & $43(43.0 \%)$ & $44(44.0 \%)$ \\
\hline $\begin{array}{l}\text { Mortality or death related to alcohol use - } \\
\text { recommended by one person and scored } 8\end{array}$ & \multicolumn{4}{|c|}{$\mathrm{N} / \mathrm{A}-$ not included in Round 1} & 93 & $18(19.4 \%)$ & $35(37.6 \%)$ & $40(43.0 \%)$ \\
\hline
\end{tabular}


Table 3. Continued

\begin{tabular}{|c|c|c|c|c|c|c|c|c|}
\hline \multirow[b]{2}{*}{ Consumption } & \multicolumn{4}{|c|}{ Round 1} & \multicolumn{4}{|c|}{ Round 2} \\
\hline & $n$ & $\begin{array}{c}\text { Scored } \\
1-3 \\
n(\%)\end{array}$ & $\begin{array}{c}\text { Scored } \\
4-6 \\
n(\%)\end{array}$ & $\begin{array}{l}\text { Scored } \\
7-9 \\
n(\%)\end{array}$ & $n$ & $\begin{array}{c}\text { Scored } \\
1-3 \\
n(\%)\end{array}$ & $\begin{array}{c}\text { Scored } \\
4-6 \\
n(\%)\end{array}$ & $\begin{array}{l}\text { Scored } \\
7-9 \\
n(\%)\end{array}$ \\
\hline $\begin{array}{l}\text { Physical health (ability to carry out physical activities } \\
\text { from basic self-care to running) }\end{array}$ & 130 & $10(7.7 \%)$ & $63(48.5 \%)$ & $57(43.8 \%)$ & 102 & $7(6.9 \%)$ & $57(55.9 \%)$ & $38(37.3 \%)$ \\
\hline Severity of the symptoms of depression or low mood & 130 & $8(6.2 \%)$ & $64(49.2 \%)$ & $58(44.6 \%)$ & 102 & $6(5.5 \%)$ & $51(59.6 \%)$ & $38(34.9 \%)$ \\
\hline Suicidal ideas or beliefs & 129 & $20(15.5 \%)$ & $72(55.8 \%)$ & $37(28.7 \%)$ & 101 & $15(14.9 \%)$ & $62(61.4 \%)$ & $24(23.8 \%)$ \\
\hline Severity of the symptoms of anxiety (feeling worried) & 130 & $16(12.3 \%)$ & $73(56.2 \%)$ & $41(31.5 \%)$ & 102 & $13(12.7 \%)$ & $71(69.6 \%)$ & $8(17.6 \%)$ \\
\hline $\begin{array}{l}\text { How often a person experiences a hangover (a range } \\
\text { of unpleasant symptoms experienced after drinking } \\
\text { alcohol that may include tiredness, thirst, nausea } \\
\text { or vomiting, trouble sleeping, low mood, }\end{array}$ & & & & & & & & \\
\hline headache, anxiety, or other aspects) & 129 & $30(23.3 \%)$ & $75(58.1 \%)$ & $24(18.6 \%)$ & 102 & $19(18.6 \%)$ & $66(64.7 \%)$ & $17(16.7 \%)$ \\
\hline Problems sleeping (either too much or too little) & 130 & $26(20.0 \%)$ & $77(59.2 \%)$ & $27(20.8 \%)$ & 101 & $21(20.8 \%)$ & $65(64.4 \%)$ & $15(14.9 \%)$ \\
\hline $\begin{array}{l}\text { Number of medical conditions someone has } \\
\text { (as diagnosed by a doctor) }\end{array}$ & 129 & $29(22.5 \%)$ & $75(58.1 \%)$ & $25(19.4 \%)$ & 102 & $24(23.5 \%)$ & $64(62.7 \%)$ & $14(13.7 \%)$ \\
\hline $\begin{array}{l}\text { Factors relating to heart health (such as blood } \\
\text { pressure) }\end{array}$ & 129 & $33(25.6 \%)$ & $73(56.6 \%)$ & $23(17.8 \%)$ & 101 & $29(28.7 \%)$ & $62(61.4 \%)$ & $10(9.9 \%)$ \\
\hline $\begin{array}{l}\text { Factors relating to obesity (such as body mass index; } \\
\text { body fat percentage) }\end{array}$ & 129 & $34(26.4 \%)$ & $76(58.9 \%)$ & $19(14.7 \%)$ & 101 & $29(28.7 \%)$ & $66(65.3 \%)$ & $10(9.9 \%)$ \\
\hline $\begin{array}{l}\text { Post-traumatic stress disorder symptoms (anxiety } \\
\text { caused by events, including upsetting memories; or } \\
\text { sleep problems; or avoiding reminders of the event) }\end{array}$ & 129 & $37(28.7 \%)$ & $74(57.4 \%)$ & $18(14.0 \%)$ & 102 & $28(27.7 \%)$ & $63(62.4 \%)$ & $10(9.9 \%)$ \\
\hline $\begin{array}{l}\text { Quality of working partnership with healthcare } \\
\text { provider }\end{array}$ & 129 & $45(34.9 \%)$ & $63(48.8 \%)$ & $21(16.3 \%)$ & 101 & $34(33.7 \%)$ & $58(57.4 \%)$ & $9(8.9 \%)$ \\
\hline $\begin{array}{l}\text { Problems with stomach or digestion (including } \\
\text { abdominal pain/swelling/vomiting/nausea) }\end{array}$ & 129 & $32(24.8 \%)$ & $78(60.5 \%)$ & $19(14.7 \%)$ & 101 & $28(27.7 \%)$ & $64(63.4 \%)$ & $9(8.9 \%)$ \\
\hline Problems with sex life & 129 & $32(24.8 \%)$ & $83(64.3 \%)$ & $14(10.9 \%)$ & 101 & $33(32.7 \%)$ & $62(61.4 \%)$ & $6(5.9 \%)$ \\
\hline Psychological factors & & & & & & & & \\
\hline $\begin{array}{l}\text { Interest in making changes around alcohol use } \\
\text { (motivation/readiness to change) }\end{array}$ & 131 & $8(6.1 \%)$ & $51(38.9 \%)$ & $72(55.0 \%)$ & 102 & $2(2.0 \%)$ & $27(26.5 \%)$ & $73(71.6 \%)$ \\
\hline $\begin{array}{l}\text { If alcohol is used to cope with stress, anxiety, or life } \\
\text { events }\end{array}$ & 130 & $12(9.2 \%)$ & $63(48.5 \%)$ & $55(42.3 \%)$ & 101 & $7(6.9 \%)$ & $50(49.5 \%)$ & $44(43.6 \%)$ \\
\hline $\begin{array}{l}\text { If the participant believes their alcohol use affects } \\
\text { their health }\end{array}$ & 130 & $13(10.0 \%)$ & $61(46.9 \%)$ & $56(43.1 \%)$ & 102 & $13(12.7 \%)$ & $46(45.1 \%)$ & $43(42.2 \%)$ \\
\hline Engaging in protective behavioral strategies & 128 & $6(4.7 \%)$ & $70(54.7 \%)$ & $52(40.6 \%)$ & 101 & $12(11.9 \%)$ & $49(48.5 \%)$ & $40(39.6 \%)$ \\
\hline Cravings or a powerful desire for alcohol & 130 & $22(16.9 \%)$ & $55(42.3 \%)$ & $53(40.8 \%)$ & 102 & $11(10.8 \%)$ & $51(50.0 \%)$ & $40(39.2 \%)$ \\
\hline $\begin{array}{l}\text { Self-efficacy or belief in ability to succeed/achieve } \\
\text { goals }\end{array}$ & 131 & $15(11.5 \%)$ & $57(43.5 \%)$ & $59(45.0 \%)$ & 102 & $9(8.8 \%)$ & $55(53.9 \%)$ & $38(37.3 \%)$ \\
\hline $\begin{array}{l}\text { Ability to refuse alcohol (sometimes called drinking } \\
\text { refusal self-efficacy or how able someone is to } \\
\text { refuse alcohol in places it may usually be } \\
\text { consumed) }\end{array}$ & 130 & $19(14.6 \%)$ & $57(43.8 \%)$ & $54(41.5 \%)$ & 102 & $8(7.8 \%)$ & $59(57.8 \%)$ & $35(34.3 \%)$ \\
\hline $\begin{array}{l}\text { Outcome expectancies; the belief that drinking leads } \\
\text { to specific positive or negative outcomes or what } \\
\text { a person expects to happen as a result of a } \\
\text { given action }\end{array}$ & 129 & $5(3.9 \%)$ & $61(46.6 \%)$ & $97(75.2 \%)$ & 102 & $14(13.7 \%)$ & $56(54.9 \%)$ & $32(31.4 \%)$ \\
\hline $\begin{array}{l}\text { Alcohol's effect on the ability to reach goals } \\
\text { (called goal striving) }\end{array}$ & 129 & $21(16.3 \%)$ & $73(56.6 \%)$ & $35(27.1 \%)$ & 101 & $14(13.9 \%)$ & $58(57.4 \%)$ & $29(28.7 \%)$ \\
\hline $\begin{array}{l}\text { Engaging in other risky behaviors (e.g., putting } \\
\text { yourself in a dangerous place/situation) }\end{array}$ & 130 & $22(16.9 \%)$ & $71(54.6 \%)$ & $37(28.5 \%)$ & 101 & $15(14.9 \%)$ & $62(61.4 \%)$ & $24(23.8 \%)$ \\
\hline Attitudes to alcohol consumption in pregnancy & 130 & $24(18.5 \%)$ & $56(43.1 \%)$ & $50(38.5 \%)$ & 101 & $21(20.8 \%)$ & $57(56.4 \%)$ & $23(22.8 \%)$ \\
\hline Feeling supported (perhaps by family and friends) & 130 & $31(23.8 \%)$ & $67(51.5 \%)$ & $32(24.6 \%)$ & 101 & $24(23.8 \%)$ & $60(59.4 \%)$ & $17(16.8 \%)$ \\
\hline How confident an individual feels; his/her self-esteem & 131 & $20(15.3 \%)$ & $71(54.2 \%)$ & $40(30.5 \%)$ & 102 & $17(16.7 \%)$ & $68(66.7 \%)$ & $17(16.7 \%)$ \\
\hline $\begin{array}{l}\text { How positively or negatively alcohol is viewed by } \\
\text { the participant }\end{array}$ & 131 & $19(14.5 \%)$ & $78(59.5 \%)$ & $34(26.0 \%)$ & 102 & $16(15.7 \%)$ & $70(68.6 \%)$ & $16(15.7 \%)$ \\
\hline $\begin{array}{l}\text { Empathy (ability to understand and share feelings } \\
\text { of another) }\end{array}$ & 126 & $54(42.9 \%)$ & $59(46.8 \%)$ & $13(10.3 \%)$ & 100 & $60(60.0 \%)$ & $35(35.0 \%)$ & $15(15.0 \%)$ \\
\hline $\begin{array}{l}\text { Engaging in healthy behaviors such as exercise } \\
\text { or healthy eating }\end{array}$ & 130 & $17(13.1 \%)$ & $76(58.5 \%)$ & $37(28.5 \%)$ & 102 & $14(13.7 \%)$ & $74(72.5 \%)$ & $14(13.7 \%)$ \\
\hline How stressed out someone feels & 130 & $23(17.7 \%)$ & $84(64.6 \%)$ & $23(17.7 \%)$ & 102 & $18(17.6 \%)$ & $70(68.6 \%)$ & $14(13.7 \%)$ \\
\hline Feeling alone or isolated & 130 & $34(26.2 \%)$ & $70(53.8 \%)$ & $26(20.0 \%)$ & 101 & $27(26.7 \%)$ & $64(63.4 \%)$ & $10(9.9 \%)$ \\
\hline Aggression or anger (either feelings or actions) & 130 & $28(21.5 \%)$ & $80(61.5 \%)$ & $22(16.9 \%)$ & 102 & $23(22.5 \%)$ & $69(67.6 \%)$ & $10(9.8 \%)$ \\
\hline $\begin{array}{l}\text { Acting impulsively (acting without thinking/ } \\
\text { considering longer term costs and benefits) }\end{array}$ & & & & & & & & \\
\hline How positively other people's alcohol use is viewed & $\begin{array}{l}131 \\
130\end{array}$ & $\begin{array}{l}38(29.0 \%) \\
39(30.2 \%)\end{array}$ & $75(57.7 \%)$ & $16(12.3 \%)$ & $\begin{array}{l}102 \\
102\end{array}$ & $\begin{array}{l}44(43.1 \%) \\
39(38.2 \%)\end{array}$ & $\begin{array}{l}55(53.9 \%) \\
61(59.8 \%)\end{array}$ & $\begin{array}{l}3(2.9 \%) \\
2(2.0 \%)\end{array}$ \\
\hline
\end{tabular}


TABLE 3. Continued

\begin{tabular}{|c|c|c|c|c|c|c|c|c|}
\hline \multirow[b]{2}{*}{ Consumption } & \multicolumn{4}{|c|}{ Round 1} & \multicolumn{4}{|c|}{ Round 2} \\
\hline & $n$ & $\begin{array}{c}\text { Scored } \\
1-3 \\
n(\%) \\
\end{array}$ & $\begin{array}{c}\text { Scored } \\
4-6 \\
n(\%) \\
\end{array}$ & $\begin{array}{c}\text { Scored } \\
7-9 \\
n(\%) \\
\end{array}$ & $n$ & $\begin{array}{c}\text { Scored } \\
1-3 \\
n(\%) \\
\end{array}$ & $\begin{array}{c}\text { Scored } \\
4-6 \\
n(\%)\end{array}$ & $\begin{array}{c}\text { Scored } \\
7-9 \\
n(\%) \\
\end{array}$ \\
\hline $\begin{array}{l}\text { Seeking new and exciting experiences (interest in } \\
\text { experiences that are new/exciting) }\end{array}$ & 131 & $47(35.9 \%)$ & $74(56.5 \%)$ & $10(7.6 \%)$ & 102 & $59(57.8 \%)$ & $41(40.2 \%)$ & $2(2.0 \%)$ \\
\hline How stressed out someone feels & 130 & $23(17.7 \%)$ & $84(64.6 \%)$ & $23(17.7 \%)$ & 102 & $18(17.6 \%)$ & $70(68.6 \%)$ & $14(13.7 \%)$ \\
\hline Intervention factors & & & & & & & & \\
\hline $\begin{array}{l}\text { If the intervention was delivered as planned or the } \\
\text { participant used the intervention }\end{array}$ & 129 & $5(3.9 \%)$ & $27(20.9 \%)$ & $97(75.2 \%)$ & 102 & $4(3.9 \%)$ & $15(14.7 \%)$ & $83(81.4 \%)$ \\
\hline $\begin{array}{l}\text { Satisfaction with intervention (the view of } \\
\text { intervention from the person taking part) }\end{array}$ & 131 & $2(1.5 \%)$ & $61(46.6 \%)$ & $68(51.9 \%)$ & 102 & $2(2.0 \%)$ & $41(40.2 \%)$ & $59(57.8 \%)$ \\
\hline $\begin{array}{l}\text { Clinician satisfaction with intervention-suggested } \\
\text { by one participant, rated } 7\end{array}$ & \multicolumn{4}{|c|}{$\mathrm{N} / \mathrm{A}-$ not included in Round 1} & 102 & $19(18.6 \%)$ & $65(63.7 \%)$ & $18(17.6 \%)$ \\
\hline
\end{tabular}

Note: $\mathrm{N} / \mathrm{A}=$ not applicable.

2003; Babor et al., 2000). Despite the lack of biomarker measures, however, our Delphi study identified outcomes across six domains, broadening the types of outcomes typically considered by any given ABI trial, while at the same time offering the possibility of standardizing outcomes across studies. This broadening highlights the importance of selecting outcome measures based on a consensus of the field rather than simply relying on what has been measured in prior research (Sinha et al., 2011).

Although our online Delphi study represents the most rigorous attempt to identify the appropriate outcome measures for $\mathrm{ABI}$ trials thus far, it is subject to some limitations. There is ambiguity as to what constitutes consensus (Sinha et al., 2011), and so our a priori choice of $70 \%$ agreement is subject to possible criticism. Although we attempted to balance perspectives within our Delphi panel, difficulties in recruiting some participant types, particularly policymakers and patients, may have skewed the overall panel recommendations toward a researcher perspective. Similarly, the predominance of English-speaking countries among our panelists, especially the United Kingdom and the United States, may also have influenced our results and suggests caution with regard to the generalizability of our findings to non-English-speaking and to low- or middle-income countries. Finally, given the nature of recruitment into our Delphi panel, it is not possible to determine the true response rate to our Round 1 invitation. This, combined with attrition between Rounds 1 and 2, may limit the validity of our results. Our use of anonymous voting and the diverse composition of our panel, however, add to what is known about outcome priorities in the ABI field.

This study is the first to identify outcomes using consensus methods for consideration in a core outcome set in ABI trials and offers itself as a major influence in the agenda setting of ABI trials. It prioritizes outcomes that are most important to a range of key stakeholders in the field and will help guide researchers in choosing outcomes in future trials. The study offers those within the field of ABIs a sig- nificant original addition to current knowledge and potential for future reproducible science work. The items prioritized here will be useful to improve evidence synthesis in future systematic reviews in the field. However, the prioritization of these outcomes is a dynamic rather than fixed process. More research is needed to (a) further prioritize these outcomes into a core outcome set for all trials of ABIs, (b) replicate this priority list over time and in underrepresented groups, (c) identify the best measures to represent these outcomes, and (d) determine if the adoption of these recommended outcomes improves standards in the field. The ORBITAL project, with oversight from the INEBRIA RMS-SIG, is pursuing these next steps.

\section{Acknowledgments}

The authors thank and acknowledge the INEBRIA RMS-SIG for feedback and useful commentary at the INEBRIA 2016 conference workshop on the topic. We are grateful to patient and public representatives who gave their views on the proposed work.

\section{References}

Allen, J. P., \& Litten, R. Z. (2003). Recommendations on use of biomarkers in alcoholism treatment trials. Alcoholism: Clinical and Experimental Research, 27, 1667-1670. doi:10.1097/01.ALC.0000091224.78880.47

Babor, T. F., McRee, B. G., Kassebaum, P. A., Grimaldi, P. L., Ahmed, K., \& Bray, J. (2007). Screening, Brief Intervention, and Referral to Treatment (SBIRT): Toward a public health approach to the management of substance abuse. Substance Abuse, 28, 7-30. doi:10.1300/J465v28n03_03

Babor, T. F., Steinberg, K., Anton, R., \& Del Boca, F. (2000). Talk is cheap: Measuring drinking outcomes in clinical trials. Journal of Studies on Alcohol, 61, 55-63. doi:10.15288/jsa.2000.61.55

Bernstein, J. A., Bernstein, E., \& Heeren, T. C. (2010). Mechanisms of change in control group drinking in clinical trials of brief alcohol intervention: Implications for bias toward the null. Drug and Alcohol Review, 29, 498-507. doi:10.1111/j.1465-3362.2010.00174.x

Blackwood, B., Ringrow, S., Clarke, M., Marshall, J., Rose, L., Williamson, P., \& McAuley, D. (2015). Core Outcomes in Ventilation Trials (COVenT): Protocol for a core outcome set using a Delphi survey with a nested randomised trial and observational cohort study. Trials, 16, 368-374. doi:10.1186/s13063-015-0905-9 
Boers, M., Tugwell, P., Felson, D. T., van Riel, P. L., Kirwan, J. R., Edmonds, J. P., . . Muirden, K. D. (1994). World Health Organization and International League of Associations for Rheumatology core endpoints for symptom modifying antirheumatic drugs in rheumatoid arthritis clinical trials. Journal of Rheumatology, Supplement, 41, 86-89.

Boulkedid, R., Abdoul, H., Loustau, M., Sibony, O., \& Alberti, C. (2011). Using and reporting the Delphi method for selecting healthcare quality indicators: A systematic review. PLoS One, 6, e20476. doi:10.1371/ journal.pone. 0020476

Chan, A. W., Tetzlaff, J. M., Altman, D. G., Laupacis, A., Gøtzsche, P. C., Krleža-Jeri , K., . . . Moher, D. (2013). SPIRIT 2013 statement: Defining standard protocol items for clinical trials. Annals of Internal Medicine, 158, 200-207. doi:10.7326/0003-4819-158-3-201302050-00583

Cumming, G. (2013). Understanding the new statistics: Effect sizes, confidence intervals, and meta-analysis. New York, NY: Routledge.

Cunningham, J. A., Shorter, G. W., Murphy, M., Kushnir, V., Rehm, J., \& Hendershot, C. S. (2017). Randomized controlled trial of a brief versus extended internet intervention for problem drinkers. International Journal of Behavioral Medicine, 24, 760-767. doi:10.1007/ s12529-016-9604-5

Davoren, M. P., Demant, J., Shiely, F., \& Perry, I. J. (2016). Alcohol consumption among university students in Ireland and the United Kingdom from 2002 to 2014: A systematic review. BMC Public Health, 16, 173. doi:10.1186/s12889-016-2843-1

Daykin, A., Selman, L. E., Cramer, H., McCann, S., Shorter, G. W., Sydes, M. R., .. . Shaw, A. J. T. (2016). What are the roles and valued attributes of a Trial Steering Committee? Ethnographic study of eight clinical trials facing challenges. Trials, 17, 307. doi:10.1186/s13063-016-1425-y

Daykin, A., Selman, L. E., Cramer, H., McCann, S., Shorter, G. W., Sydes, M. R., . . . Shaw, A. J. T. (2017). 'We all want to succeed, but we've also got to be realistic about what is happening': An ethnographic study of relationships in trial oversight and their impact. Trials, 18, 612. doi:10.1186/s13063-017-2305-9

Eleftheriadou, V., Thomas, K., van Geel, N., Hamzavi, I., Lim, H., Suzuki, T., . . . Ezzedine, K., \& the Vitiligo Global Issues Consensus Group. (2015). Developing core outcome set for vitiligo clinical trials: International e-Delphi consensus. Pigment Cell \& Melanoma Research, 28, 363-369. doi:10.1111/pcmr.12354

Gargon, E., Williamson, P. R., Altman, D. G., Blazeby, J. M., Tunis, S., \& Clarke, M. (2017). The COMET Initiative database: Progress and activities update (2015). Trials, 18, 54. doi:10.1186/s13063-017-1788-8

Guyatt, G. H., Oxman, A. D., Kunz, R., Atkins, D., Brozek, J., Vist, G., . . Schünemann, H. J. (2011). GRADE guidelines: 2. Framing the question and deciding on important outcomes. Journal of Clinical Epidemiology, 64, 395-400. doi:10.1016/j.jclinepi.2010.09.012

Hasson, F., \& Keeney, S. (2011). Enhancing rigour in the Delphi technique research. Technological Forecasting and Social Change, 78, 1695-1704. doi:10.1016/j.techfore.2011.04.005

Hasson, F., Keeney, S., \& McKenna, H. (2000). Research guidelines for the Delphi survey technique. Journal of Advanced Nursing, 32, 1008-1015.

Henihan, A. M., Klimas, J., Bury, G., O’Toole, T., Rieckman, T., Shorter, G., \& Cullen, W. (2015). Methodological challenges and issues of recruiting for mental health and substance use disorders trials in primary care [Abstract]. Addiction Science \& Clinical Practice, 10, Supplement 1, A21. doi:10.1186/1940-0640-10-S1-A21

Henihan, A. M., McCombe, G., Klimas, J., Swan, D., Leahy, D., Anderson, R., . . Cullen, W. (2016). Feasibility of alcohol screening among patients receiving opioid treatment in primary care. BMC Family Practice, 17, 153. doi:10.1186/s12875-016-0548-2

Hula, W. D., Fergadiotis, G., \& Doyle, P. J. (2014). A core outcome set for aphasia treatment research: Obstacles, risks, and benefits. Aphasiology, 28, 1396-1399. doi:10.1080/02687038.2014.930264

Kaner, E. F. S., Beyer, F. R., Muirhead, C., Campbell, F., Pienaar, E. D., Bertholet, N., . . B Burnand, B. (2018). Effectiveness of brief alcohol interventions in primary care populations. Cochrane Database of Systematic Reviews, Issue 2, Article No. CD004148. doi:10.1002/14651858. CD004148.pub4

Khadjesari, Z., Murray, E., Hewitt, C., Hartley, S., \& Godfrey, C. (2011). Can stand-alone computer-based interventions reduce alcohol consumption? A systematic review. Addiction, 106, 267-282. doi:10.1111/j.1360-0443.2010.03214.x

Kypri, K. (2007). Methodological issues in alcohol screening and brief intervention research. Substance Abuse, 28, 31-42. doi:10.1300/ J465v28n03_04

Moher, D., Schulz, K. F., \& Altman, D. G. (2001). The CONSORT statement: Revised recommendations for improving the quality of reports of parallel-group randomised trials. The Lancet, 357, 1191-1194. doi:10.1016/S0140-6736(00)04337-3

Mokkink, L. B., Prinsen, C. A., Bouter, L. M., Vet, H. C., \& Terwee, C. B. (2016). The COnsensus-based Standards for the selection of health Measurement INstruments (COSMIN) and how to select an outcome measurement instrument. Brazilian Journal of Physical Therapy, 20, 105-113. doi:10.1590/bjpt-rbf.2014.0143

National Institute for Health and Care Excellence. (2010). NICE Public Health Guideline 24 (PH24): Alcohol-use disorders: Prevention. Retrieved from http://www.nice.org.uk/PH24

Schmitt, J., Langan, S., Stamm, T., \& Williams, H. C., \& the Harmonizing Outcome Measurements in Eczema (HOME) Delphi panel. (2011). Core outcome domains for controlled trials and clinical recordkeeping in eczema: International multiperspective Delphi consensus process. Journal of Investigative Dermatology, 131, 623-630. doi:10.1038/jid.2010.303

Shorter, G., Newbury- Birch, D., Heather, N., Giles, E., Holloway, A., Bray, J., ... O'Donnell, A. (2016). Systematic review to identify and appraise outcome measures and domains used in trials evaluating alcohol screening and brief interventions: The Outcome Reporting in Brief Intervention Trials (ORBIT) project review. Retrieved from https://www.crd.york. ac.uk/PROSPERO/display_record.php?RecordID $=47185$

Shorter, G. W., Heather, N., Bray, J. W., Giles, E. L., Holloway, A., Barbosa, C., . . Newbury-Birch, D. (2017). The 'Outcome Reporting in Brief Intervention Trials: Alcohol' (ORBITAL) framework: Protocol to determine a core outcome set for efficacy and effectiveness trials of alcohol screening and brief intervention. Trials, 18, 611. doi:10.1186/ s13063-017-2335-3

Shorter, G. W., Bray, J. W., Giles, E. L., Heather, N., Berman, A. H., O'Donnell, A. J., et al. (2019). The variability of outcomes used in efficacy and effectiveness trials of alcohol brief interventions: A systematic review. Journal of Studies on Alcohol and Drugs, 80, 286-298. doi:10.15288/jsad.2019.80.286

Sinha, I. P., Smyth, R. L., \& Williamson, P. R. (2011). Using the Delphi technique to determine which outcomes to measure in clinical trials: Recommendations for the future based on a systematic review of existing studies. PLoS Medicine, 8, e1000393. doi:10.1371/journal. pmed. 1000393

White, A., Kavanagh, D., Stallman, H., Klein, B., Kay-Lambkin, F., Proudfoot, J., . . Young, R. (2010). Online alcohol interventions: A systematic review. Journal of Medical Internet Research, 12, e62. doi:10.2196/ jmir. 1479

Williamson, P. R., Altman, D. G., Bagley, H., Barnes, K. L., Blazeby, J. M., Brookes, S. T., . . Young, B. (2017). The COMET Handbook: Version 1.0. Trials, 18, Supplement 3, 280. doi:10.1186/s13063-017-1978-4

Williamson, P., Altman, D., Blazeby, J., Clarke, M., \& Gargon, E. (2012). Driving up the quality and relevance of research through the use of agreed core outcomes. Journal of Health Services Research \& Policy, 17, 1-2. doi:10.1258/jhsrp.2011.011131

Williamson, P., \& Clarke, M. (2012, April 13). The COMET (Core Outcome Measures in Effectiveness Trials) Initiative: Its role in improving Cochrane Reviews. Cochrane Database of Systematic Reviews, Issue 5, Article No. ED000041. 